\title{
INOVASI PRAKTIKUM KIMIA BAHAN ALAM DENGAN MEMANFAATKAN KEARIFAN LOKAL SUKU SASAMBO
}

\section{INNOVATION IN NATURAL PRODUCT CHEMISTRY LABORATORY BY UTILIZING LOCAL WISDOM OF THE SASAMBO}

\author{
Aliefman Hakim¹, A. Wahab Jufri², Jamaluddin², Muhammad Eka Putra Ramandha ${ }^{3}$ \\ ${ }^{1}$ Program Studi Pendidikan Kimia FKIP, Universitas Mataram, Mataram, Indonesia \\ ${ }^{2}$ Program Studi Pendidikan Biologi FKIP, Universitas Mataram, Mataram, Indonesia \\ ${ }^{3}$ Program Studi Magister Pendidikan IPA, Universitas Mataram, Mataram, Indonesia \\ Email: Aliefmanhakim27@gmail.com
}

Diterima: 19 Juni 2020. Disetujui: 21 Juni 2020. Dipublikasikan: 30 September 2020

\begin{abstract}
Abstrak: Praktikum Kimia Bahan Alam (KBA) dengan memanfaatkan kearifan lokal suku SASAMBO berupa berbagai jenis tumbuhan obat. Studi literatur yang terdiri atas tahapan data display, data reduction, dan conclusion telah dilakukan dalam menyusun praktikum bahan alam ini. Data tersebut berupa hasil isolasi senyawa metabolit sekunder dari tanaman obat tradisional SASAMBO dan data efektivitas metode praktikum kimia. Metode isolasi yang digunakan terdiri atas ekstraksi, fraksinasi dan pemurnian. Prosedur isolasi menekankan pada praktikum skala laboratorium dan cocok untuk perkuliahan KBA. Pembelajaran KBA lebih efektif jika menggunakan metode praktikum yang dapat mengembangkan keterampilan pengambilan keputusan peserta didik melalui berbagai alternatif pilihan dalam proses isolasi metabolit sekunder. Hal ini disebabkan konsep praktikum KBA menuntut mahasiswa dapat menentukan prosedur isolasinya secara mandiri dengan rujukan artikel-artikel penelitian.
\end{abstract}

Kata kunci: Praktikum, kimia bahan alam, isolasi senyawa metabolit sekunder

Abstrak: Natural Product Chemistry (NPC) by utilizing the local wisdom of the SASAMBO in the form of various types of medicinal plants. Literature studies consisting of data display, data reduction, and conclusion have been carried out in compiling this natural material practicum. The data is the result of isolation of secondary metabolites from traditional medicinal plants SASAMBO and data on the effectiveness of the chemical laboratory method. The isolation method used consisted of extraction, fractionation and purification. The isolation procedure emphasizes on a laboratory scale and is suitable for NPC lectures. NPC learning is more effective if it uses practicum methods that can develop students' decision-making skills through various alternative choices in the secondary metabolite isolation process. This is because the concept of NPC laboratory requires students to independently determine the isolation procedure with references to research articles.

Keywords: Laboratory, natural product chemistry, isolation, secondary metabolites

\section{PENDAHULUAN}

Kimia Bahan Alam (KBA) merupakan ilmu yang menganalisis senyawa metabolit sekunder dari suatu organisme [1]. Konsep dalam pembelajaran KBA yaitu analisis, isolasi, dan pemurnian senyawa metabolit sekunder. Objek isolasi dalam KBA adalah tanaman, khususnya tanaman obat [2].

Tanaman obat tradisional banyak dimiliki berbagai daerah di Indonesia, khususnya di daerah Nusa Tenggara Barat (NTB). Masyarakat NTB terbagi menjadi 3 suku yaitu suku SASAMBO (Sasak Samawa Mbojo). Masing-masing suku tersebut memiliki berbagai tanaman obat tradisioal. Tanaman obat tradisional suku Sasak tertulis rapi dalam naskah lontar peninggalan nenek moyang, yang terdapat sekitar 163 tumbuhan obat $[3,16]$. Suku Samawa juga yang menyimpan berbagai jenis tanamana obat, sedikitnya ada 40 tanaman obat teridentifikasi dan digunakan oleh masyarakat lokal [4]. Suku Mbojo juga memiliki tanaman obat tradisional, terdapat sekitar 45 jenis tanaman obat yang digunakan secara turun-temurun oleh masyarakat suku mbojo (Bima) [5].

Salah satu tanaman tradisional khas Sasak yaitu daun telingan bangket/pegagan. Tanaman pegagan termasuk dalam 50 jenis tanaman obat utama. Beberapa khasiat tanaman pegagan adalah sebagai obat lemah syaraf, demam, bronkhitis, kencing manis, psikoneurosis, wasir, dantekanan darah tinggi, penambah nafsu makan, dan untuk menjaga vitalitas [6].

Tanaman obat tradisional digunakan berdasarkan kepercayaan turun-temurun masyarakat setempat. Namun masyarakat tidak mengetahui 
kandungan dari obat tradisional yang digunakan. Dengan metode isolasi dan identifikasi senyawa pada pembelajaran KBA, maka dapat diketahui manfaat dan kegunaan dari tanaman obat tersebut [7].

Mata kuliah Kimia Bahan Alam (KBA) dalam jenjang strata 1 di Indonesia lebih efektif jika menggunakan metode praktikum [8]. Praktikum dapat mengembangkan kemampuan berpikir tingkat tinggi siswa, hal ini disebabkan karena melalui kegiatan praktikum siswa dibimbing untuk melakukan proses yang dapat menunjang kemampuan berpikir dan pengambilan keputusan [9].

Tujuan Penelitian ini yaitu mengintegrasi tumbuhan obat SASAMBO dalam praktikum Kimia Bahan Alam (KBA) untuk mengembangkan keterampilan pengambilan keputusan

\section{METODE}

Metode penelitian yang digunakan adalah metode studi literatur yang terdiri dari data display, data reduction, dan conclusion. Sumber data berasal dari beberapa artikel ilmiah. Data dari beberapa artikel ilmiah yang akan dianalisis dalam dalam artikel ini yaitu: (1) data metode dan hasil isolasi tanaman obat, (2) data efektivitas metode praktikum dalam mengembangkan kemampuan pengambilan keputusan

\section{HASIL DAN PEMBAHASAN}

Hasil penelitian yang menggabungkan data dari berbagai jurnal ilmiah dianalisis sebagai berikut. Isolasi senyawa metabolit sekunder terdiri atas ekstraksi, fraksinasi, pemurnian, dan elusidasi struktur senyawa metabolit sekunder. Berikut diuraikan contoh isolasi asam brahmat dari daun telingan bangket/pegagan hijau.

Adapun langkah-langkah dalam ekstraksi yaitu: (1) Mengeringkan daun telingan bangket/pegagan hijau dibawah sinar matahari. (2) Daun telingan bangket/pegagan hijau yang telah dikeringkan, selanjtunya dihaluskan dengan cara ditumbuk/diblender. Tujuan dihaluskannya daun pegagan ini yaitu agar memudahkan dalam mengikat senyawa yang terkandung didalam daun pegagan tersebut. (3) Menimbang sampel daun telingan bangket/pegagan hijau sebanyak 300 g. (4) Memasukkan ke dalam wadah maserasi (toples). Merendam sampel daun pegagan kering dengan pelarut methanol selama 3 x 24 jam. Tujuan penambahan pelarut metanol disebabkan pelarut metanol bersifat universal. Sifat universal ini membuat pelarut methanol dapat menarik senyawa yang bersifat non polar, polar, semi polar [10]. (5) Menyaring sampel daun pegagan menggunakan kain blacu kemudian mengambil ekstrak sampel. (6) Memasukkan filtrat dalam labu evaporator kemudian mengevaporasi sampai diperoleh ekstrak kental.
Setelah dilakukan ekstraksi selanjutnya dilakukan proses pemurnian, adapun langkah-langkah pemurnian daun pegagan sebagai berikut: (1) Ekstrak kental metanol dilarutkan dengan akuades panas. Menggunakan akuades panas ini bertujuan untuk melarutkan senyawa-senyawa yang larut dalam air atau bersifat polar. (2) Kemudian didinginkan, (3) Dilakukan penyaringan, penyaringan dilakukab agar senyawa-senyawa yang larut dalam air akan terpisah dari bagian filtratnya. (4) Endapan yang diperoleh dilarutkan kembali dengan pelarut metanol, untuk melarutkan kembali senyawa-senyawa yang tidak larut oleh air. (5) Filtrat yang diperoleh ditambahkan karbon aktif yang telah dipanaskan dengan oven pada suhu $105{ }^{\circ} \mathrm{C}$ selama kurang lebih 4 jam hingga suhu oven kembali. (6) Tambahkan karbon aktif sedikitdemisedikit. (7) aduk campuran tersebut. (8) kemudian biarkan filtrat hingga bening. Penambahan karbon aktif ini bertujuan untuk menarik klorofil dan pengotor lainnya. (9) Kemudian disaring dengan kertas saring dua lapis, (10) hasil filtrat jernih diuapkan kembali dengan in vacuo hingga kering dan didapatkan serbuk triterpenoid dalam bentuk serbuk putih kekuningan. (11) Kemudian dilakukan uji KLT dengan eluen cloroform: metanol 4:1. Penampak noda dengan memakai pereaksi asam sulfat pekat $10 \%$ (12) kemudian semprotkan penampak noda pada plat KLT. Selanjutnya spot yang terbentuk pada hasil KLT di identifikasi struktur senyawa triterpenoid dengan metode spektroskopi resonansi magnetik inti (RMI-H) pada 500 MHz. Sinyal pada $\delta \quad 3,72$ mengindikasikan proton pada posisi H-3. Sinyal proton hidroksi metil $\left(\mathrm{CH}_{2} \mathrm{OH}\right)$ pada $\delta 3,78$ dan $\delta 3,99$ mengindikasikan proton pada posisi 23. Sinyal multiplet pada $\delta 4,22$ dan $\delta$ 4,24 mengindikasikan proton pada posisi 6 dan posisi 2. Sedangkan sinyal pada $\delta 5,45$ adalah karakteristik untuk sinyal dari proton pada C-12 triterpen. Berdasarkan uraian di atas, dapat diusulkan struktur yang teridentifikasi adalah 2a,3ß,6ß,23tetrahidroksi-28-oat-12en dengan nama asam brahmat [11].

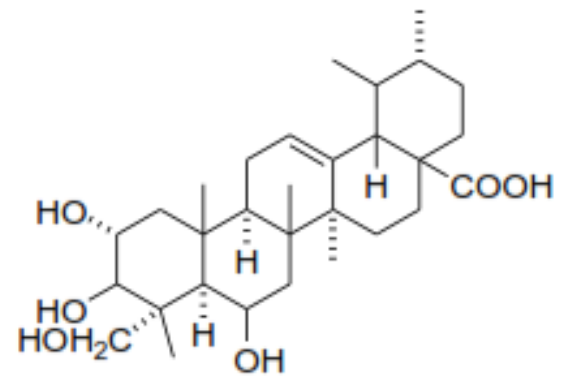

Gambar 1. Struktur Asam Brahmat [1] 
Asam brahmat seperti ditujukkan dalam Gambar 1 merupakan senyawa turunan dari gugus triterpenoid. Triterpenoid merupakan golongan senyawa terbesar dalam kelas terpenoid yang dibentuk oleh kerangka karbon, terdiri dari 6 unit isopren dan didalam biositesanya diturunkan dari hidrokarbon C30 asiklik, yaitu skualen. Senyawa ini berstruktur siklik nisbi yang rumit, kebanyakan berupa alkohol, aldehid, atau asam karboksilat. Triterpenoid banyak berupa senyawa tak berwarna dan titik lelehnya tinggi. Sebagian besar triterpenoid mempunyai 4 atau 5 cincin yang bergabung dengan pola yang sama. Sedangkan gugus fungsinya dapat berupa senyawa tertentu, seperti adanya ikatan rangkap, gugus keton, gugus asetoksi, cincin oksida atau lakton [10].

Daun Telingan bangket atau pegagan hijau biasa digunakan oleh masyarakat suku Sasak untuk obat luka dan tubercolosis. (Soedarsono, R \& Andayaningsih, D. 2008). Pegagan mampu mengobati berbagai penyakit yang mematikan seperti kanker dan penyakit tuberkulosis, hal ini disebabkan karena pegagan mengandung golongan senyawa triterpen. Senyawa triterpen ini merupakan metabolit sekunder yang memiliki potensi untuk menghambat bakteri patogen yang merupakan sumber penyebab penyakit tuberculosis [12].

Metode identifikasi kandungan senyawa dalam obat tradisional seperti daun telingan bangket/pegagan hijau dapat digunakan dalam praktikum KBA, hal ini disebabkan karena metode dan bahan-bahan yang digunakan mudah didapatkan. Hal ini sesuai dengan prinsip pembelajaran KBA yaitu menuntut kemampuan analisis dan keterampilan dalam mengisolasi dan pemurnian senyawa.

Hasil penelitian Hakim, [13], menunjukkan rata-rata n-gain keterampilan berpikir kritis kelas eksperimen berbasis mini project yaitu 0,58 sedangkan kelas kontrol 0,37. Hasil n-gain tertinggi kelas eksperimen yaitu 0,70 terdapat pada indikator menentukan suatu tindakan (memilih kriteria untuk mempertimbangkan solusi yang tepat), sedangkan yang terendah yaitu 0,47 terjadi pada indikator membuat dan menentukan nilai pertimbangan (menimbang dan membuat keputusan).

Peneltian Novalia, [14] menunjukkan hasil bahwa pembelajaran dengan menggunakan metode praktikum meningkatkan daya belajar dan kemampuan siswa. Praktikum merupakan metode yang berguna bagi mata kuliah abstrak seperti KBA. [15]. Data pengaruh praktikum berbasis kearifan lokal terhadap literasi sains siswa menunjukkan peningkatan sebesar $37 \%$ sedangkan untuk siswa yang tidak menggunakan perlakuan/ kelas kontrol peningkatan hanya 25\%. (Sapitri, R.D., dkk, 2020). Praktikum berbasis kearifan lokal meningkatkan dan menumbuhkan kepedulian siswa dalam menjaga dan memanfaatkan sumber daya lokal yang dimiliki.

Dari data tersebut terlihat bahwa, menggunakan praktikum mini project menumbuhkan minat dan memberikan stimulus kepada peserta didik untuk dapat menimbang dan mengambil keputusan yang dilakukan. Contohnya: peserta didik memilih metode isolasi yang tepat, bahan-bahan yang tidak berbahaya, dan cara identifikasi senyawa metabolit sekunder yang baik.

Mata kuliah KBA lebih efektif jika dibelajarkan dengan metode praktikum, hal ini dikarenakan metode praktikum menuntut peserta didik untuk dapat memahami konsep dan menyelesaikan permasalahan yang diberikan [8]. Metode praktikum juga dapat menghilangkan miskonsepsi pada peserta didik melalui konflik. Contohnya peserta didika akan mengalami konflik dalam pemikirannya jika hipotesis yang telah ditentukan berbeda dengan hasil praktikum yang dilakukan. Dalam praktikum peserta didik dituntut untuk berpikir tentang apa yang mereka lakukan dan mengapa mereka melakukannya, hal ini menjadikan metode praktikum dapat mengembangkan keterampilan generik sains dan keterampilan berpikir kritis peserta didik. Pengembangan kemampuan pengambilan keputusan dilakukan melalui implementasi dan evaluasi prosedur yang didesain sendiri oleh peserta didik. [9].

\section{KESIMPULAN}

Pengintegrasian tanaman obat tradisional dalam praktikum KBA mampu memberikan stimulus pada mahasiswa untuk mampu mengambil keputusan yang tepat. Hal tersebut disebabkan karena konsep pembelajaran KBA menggunakan metode praktikum. Dalam kegiatan praktikum ini mahasiswa menentukan sendiri bahan dan metode isolasi senyawa, namun tetap bersumber pada artikel-artikel ilmiah.

\section{UCAPAN TERIMA KASIH}

Terima kasih disampaikan kepada Kementrian Pendidikan dan Kebudayaan Republik Indonesia yang telah mendanai penelitian ini.

\section{DAFTAR PUSTAKA}

[1] Visht, S. \& Chaturvedi, S. 2012. Isolation of Natural Products. Current Pharma Research. 2(3), 584-599.

[2] Dewi, N. L. A., Adnyani, L. P. S., Pratama, R. B. R., Yanti, N. N. D., Manibuy, J. I., \& Warditiani N. K. 2018. Pemisahan, Isolasi, dan Identifikasi Senyawa Saponin dari Herba Pegagan (Centella asiatica L. Urban). Jurnal Farmasi Udayana. 7 (2), 68-76.

[3] Yamin M., Burhanudin, Jamaluddin, Nasruddin. Pengobatan Dan Obat Tradisional Suku Sasak Di 
Lombok. 2018. Jurnal Biologi Tropis. 18 (1), 112.

[4] Jannah, H \& Safnowandi. Identifikasi jenis tumbuhan obat tradisional di Kawasan hutan olat cabe desa batu bangka kecamatan moyo hilir kabupaten sumbawa besar. 2018. Bioscientist: Jurnal Ilmiah Biologi. 6 (2), 145-172.

[5] Ani, N., Rohyani, S.I., \& Maulana. 2018. Pengetahuan Masyarakat Tentang Jenis Tumbuhan Obat Di Kawasan Taman Wisata Alam Madapangga Sumbawa. J. Pijar MIPA. 13 (2), 160-166

[6] Sutardi. 2016. Kandungan Bahan Aktif Tanaman Pegagan Dan Khasiatnya Untuk Meningkatkan Sistem Imun Tubuh. Jurnal Litbang Pertanian. 35 (3), 121-130.

[7] Liliasari. (2008). Peningkatan kualitas pendidikan kimia dari pemahaman konsep kimia menjadi berpikir kimia, Makalah Seminar UNY.

[8] Hakim, H., Liliasari., Kadarohman, A., Syah, M.Y., \& Musthapa, I. 2015. Pembelajaran Kimia Bahan Alam Inovatif Melalui Praktikum. Prosiding Seminar Nasional "Arah Pendidikan MIPA Masa Depan; Antara Harapan dan Kenyataan"

[9] Schafer, A.G.L., \& Yezierski, E.J., 2019. Chemistry critical friendships: investigating chemistry specific discourse within a domaingeneral discussion of best practices for inquiry assessments. J. Chem. Educ.

[10] Mora, E \& Fernando, A. 2012. Optimasi Ekstraksi Triterpenoid Total Pegagan (Centella asiatica (Linn.) Urban) yang Tumbuh di Riau. Jurnal Penelitian Farmasi Indonesia. 1(1), 11-16

[11] Howan, D. H. O. (2017). Isolasi dan identifikasi metabolit sekunder dari ekstrak butanol pegagan [Centella asiatica (L) urban]. Fullerene Journal of Chemistry, 2(2), 92-95.

[12] Yusron, Ilyas, A., \& Saleh, H.A. 2016. Bioaktivitas ekstrak metanol daun pegagan (centella asiatica 1.) Terhadap Pertumbuhan Bakteri Mycobacterium Tuberculosis. Jurnal AlKimia. 4 (1), 54-61.

[13] Hakim, H., Liliasari., Kadarohman, A., \& Syah, M.Y. 2016. Improvement of Student Critical Thinking Skills with the Natural Product Mini Project Laboratory Learning. Indones. J. Chem. 16 (3), $322-328$.

[14] Novalia, R., Fadiawati, N., \& Rosilawati I. 2015. Pengembangan Instrumen Asesmen Kinerja Pada Praktikum Pengaruh Konsentrasi Terhadap Laju Reaksi. Jurnal Pendidikan dan Pembelajaran Kimia. 4 (2), 568-580.
[15] Luckie, D.B., Mancini, B.W., Abdallah, N., Kadouh, A.K., Ungkuldee, A.C.P., \& Hare, A.A. 2020. Undergraduate teaching assistants can provide support for reformed practices to raise student learning. Advances in Physiology Educatio. 44, 32-38.

[16] Sapitri, R.D., Hadisaputra, S., \& Junaidi, E. 2020. Pengaruh Praktikum berbasis kearifan lokal terhadap keterampilan literasi sains dan hasil belajar. Jurnal Pijar MIPA. 15 (2), 122-129. 